(International Journal of Agriculture and Wildlife Science)
http://dergipark.org.tr/jaws

Araştırma Makalesi

\title{
Pelemir (Cephalaria syriaca L.) Bitkisinin Bazı Bitkisel Özelliklerinin ve Tohum Yağı Kompozisyonlarının Belirlenmesi
}

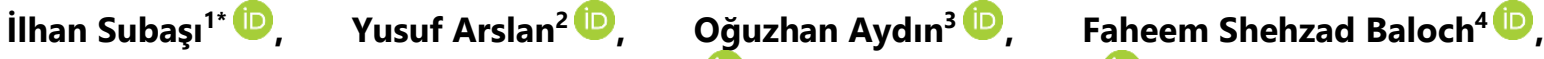 \\ Mahmut Çamlıca ${ }^{\text {(i) }}$, Vahdettin Çiftçi
}

${ }^{1}$ Bolu Abant İzzet Baysal Üniversitesi Ziraat Fakültesi, Tohum Bilimi ve Teknolojisi Bölümü, Bolu

${ }^{2}$ Bolu Abant İzzet Baysal Üniversitesi Ziraat Fakültesi, Tarla Bitkileri Bölümü, Bolu

${ }^{3}$ Tarla Bitkileri Merkez Araştırma Enstitüsü Müdürlüğü, Yağlı Tohumlu Bitkiler Birimi, Yenimahalle, Ankara

${ }^{4}$ Sivas Bilim ve Teknoloji Üniversitesi, Bitkisel Üretim ve Teknolojileri Bölümü, Sivas

Geliş tarihi (Received): 13.12.2020Ｋabul tarihi (Accepted): 27.02.2021

\begin{abstract}
Anahtar kelimeler: Pelemir, Cephalaria syriaca L., tohum verimi, yağ oranı, yağ verimi
\end{abstract}

*Sorumlu yazar ilhan.subasi@ibu.edu.tr
Özet. Bu çalışma pelemir (Cephalaria syriaca L.) genotiplerinin (Adana-1, Sivas-1, Karahan) Bolu ili ekolojisindeki performanslarının tespit edilmesi amacıyla 2016-2017 ve 2017-2018 yıllarında yürütülmüştür. Denemeler tesadüf blokları deneme deseni ile 3 tekrarlı olarak gerçekleştirilmiştir. Çalışmada; bitki boyu, olgunlaşma gün sayısı, 1000 tane ağırlığı, dekara tohum verimi, yağ oranı ve dekara yağ verimi özellikleri incelenmiştir. Araştırmada; bitki boyu (cm), olgunlaşma gün sayısı, 1000 tohum ağırlığı (g), dekara tohum verimi $\left(\mathrm{kg} \mathrm{da}^{-1}\right)$, yağ oranı (\%) ve yağ verimi $\left(\mathrm{kg} \mathrm{da}^{-1}\right)$ değerleri sırasıyla; 109.0-171.0 cm, 215-291 gün, 14-22 g, 52.5-219.0 kg da-1 $\% 19.11-26.12$ ve 13.71-44.11 kg da-1 aralığında gerçekleşmiştir. Sivas-1 genotipinin erken olgunlaşma, düşük 1000 tane ağırlığı, düşük verim ve yüksek yağ oranı ile diğer genotiplerden çok farklı olduğu görülmüştür. Pelemir genotiplerinin yağ asidi kompozisyonları incelenmiş ve \%14.8-15.5 arasında miristik asit, \%7.5-7.7 arasında cis-10-Pentadecanoic asit, \%29.8- 30.0 arasında oleik asit ve \%29.8-30.6 arasında linoleik asit içerdiği tespit edilmiştir. Araştırmada kullanılan genotiplerin yağ oranları, tohum ve yağ verimleri dikkate alındığında, Sivas-1 genotipi yağ oranı bakımından öne çıkarken tohum ve yağ veriminde Karahan çeşidi öne çıkmıştır.

\section{Determination of Some Plant Traits and Seed Oil Compositions of Cephalaria syriaca L.}

\section{Keywords:}

Cephalaria syriaca L.,

Syrian scabious, seed yield, oil content, fatty acids compositions.

\begin{abstract}
This study was conducted to determine the performance of some Pelemir (Cephalaria syriaca L.) genotype (Adana-1, Sivas-1, Karahan) under Bolu ecological condition in 2016-2017 and 2017-2018. The field experiments were carried out in the randomized complete block design with three replications. Plant height, number of days to maturity, thousand seed weight, seed yield, oil content and oil yield were investigated in the study. Mean data for plant height (cm), number of days to maturity, 1000 seed weight ( $\mathrm{g}$ ), oil content (\%), seed yield $\left(\mathrm{kg} \mathrm{da}^{-1}\right)$ and oil yield $\left(\mathrm{kg} \mathrm{da}^{-1}\right)$ were 109.0-171.0 cm, 215-291 days, $14-22 \mathrm{~g}, 52.5-219.0 \mathrm{~kg} \mathrm{da}^{-1}$, $19.11-26.12 \%$ and $13.71-44.11 \mathrm{~kg} \mathrm{da}^{-1}$ respectively. It has been observed that Sivas-1 genotype is very different from other genotypes with its early ripening, low 1000 seed weight, low yield and high oil content. Fatty acid compositions of Pelemir genotypes were examined and it was found that they contain $14.8-15.5 \%$ myristic acid, $7.5-7.7 \%$ cis-10-Pentadecanoic acid, $29.8-30.0 \%$ oleic acid and $29.8-30.6 \%$ linoleic acid.Considering the oil ratios, seed and oil yields of the genotypes used in the study, Sivas-1 genotype was higher in terms of oil ratio, while the Karahan variety gave higher results in seed and oil yield than other genotypes.
\end{abstract}




\section{GíRiş}

Türkiye her yıl ihtiyacının yaklaşık yarısı kadar yurt dışından yağlı tohum ve türeleri (ham yağ ve yağlı tohum küspesi) alımı yapmaktadır. 2019 yıında istatistiksel verilere göre yurt dışından 2,457 milyar dolar tutarında yağıı tohum, yemeklik yağ ve yağlı tohum küspesi ithal etmiştir (TÜiK, 2019). Türkiye'de ham yağ, yağlı tohum küspesi ve biyodizel hammaddesi ihtiyacını karşılamanın yolu yağ bitkileri ekim alanını Trakya bölgesinin yanı sıra iç Anadolu, Orta Anadolu ve Doğu Anadolu bölgelerinde de yaygınlaştırmaktan geçmektedir. Türkiye'nin her bölgesinde yaygın olarak yağ bitkileri yetiştiriciliğinin yapılabilmesi için de alternatif yağ bitkilerinin tarımının geliştirilmesi gerekmektedir (Arıoğlu ve ark., 2010; Katar ve ark., 2011; Arslan ve ark., 2012; Katar ve ark., 2012; Arslan ve ark., 2014). Pelemir (Cephalaria syriaca L.) bitkisi soğuğa, kuraklığa ve tuzluluğa dayanıkı bir bitkidir. Daha önceleri yabancı ot olarak bilinen pelemir bitkisi 2017 yılında Türkiye Milli Çeşit Listesi'nde yerini almış ve kültür bitkisi olarak değerlendirilmiştir. Halihazırda, biri yağlık (Karahan), diğeri ise gıda katkısı amacıyla (Ziya) iki adet çeşit de tescil ettirilmiştir (TTSM, 2017). Pelemir bitkisi soğuğa aynı zamanda kurağa dayanıklı olduğundan gelecek için potansiyel bir alternatif yağ bitkisidir.

Pelemir yağı yeşil-sarı renge ve hoş bir kokuya sahiptir. Doğrudan yemeklik olarak kullanılmış olan bu yağ diğer yağlarla karışım yapılarak da kullanıımıştır. Ancak pelemir yağında var olduğu bildirilen \%7-8 oranında epoksi asit, yağın bu haliyle yemeklik olarak kullanılmasının uygun olmayacağını göstermektedir (Yazıcıoğlu ve ark., 1978). Epoksi yağ asitleri sekonder oksidasyon ürünleri olup insanlar tarafından metabolize edildikten sonra toksine dönüşebilen protoksinlerdir (Mubiru ve ark., 2013). Yağı \%19-20 oranında miristik asit içermesi nedeniyle sabun sanayi için oldukça elverişli olan pelemirin içerdiği epoksi asitler nedeniyle deri ve tekstil sanayinde kullanılması uygundur. Pelemir yağının biyodizel üretimi açısından uygun olduğu gösterilmiştir (Öğüt ve ark. 2014). Ayrıca yağı alınmış küspesi yem sanayiinde kullanılma potansiyeli olan protein kaynağıdır (Yazıcıoğlu ve ark. 1978; Katar ve ark. 2012). Pelemir tohum unu ve yağının düşük düzeylerde (\%0.5-3.0) buğday ununa karıştırılması ekmeğin bayatlamasını geciktirmekte ve hamurun daha iyi kabarmasına sebep olmaktadır (Karaoğlu, 2006).

Bu çalışmanın amacı Bolu ili koşullarında farklı pelemir genotiplerinin bazı bitkisel özellikleri ile yağ oranı ve yağ asitleri kompozisyonlarının belirlenerek bu özellikler bakımından karakterize edilmesidir.

\section{MATERYAL VE METOT}

Çalışmada materyal olarak Tarla Bitkileri Merkez Araştırma Enstitüsü Müdürlüğü'ne ait olan Karahan çeşidi ile yine aynı Enstitüde Sivas ve Adana populasyonlarından seleksiyonla saflaştırılan Sivas-1 ve Adana-1 hatları kullanılmıştır. Deneme, Abant İzzet Baysal Üniversitesi, Ziraat ve Doğa Bilimleri Fakültesi Deneme Tarlasında, Tesadüf Blokları Deneme Desenine göre üç tekrarlı kurulmuştur. Ekimler, 1 Ekim tarihinde yapılmış, her parsel 5 m uzunluğunda ve $1.8 \mathrm{~m}$ genişliğinde eşit parsellerde, sıra arası $30 \mathrm{~cm}$ sıra üzeri $10 \mathrm{~cm}$ ve 6 sıra olacak şekilde yapılmıştır. Yabancı ot mücadelesi ve diğer bazı kültürel işlemler elle gerçekleştirilmiştir. Hasat, birinci yıl 21.07.2017 tarihinde, ikinci yıl ise 06.08.2018 tarihinde parsel biçerdöveri ile yapılmıştır. Yağ oranları ve yağ asidi kompozisyonu analizleri Ankara Tarla Bitkileri Merkez Araştırma Enstitüsü Yağ Analiz Laboratuvarı'nda yapılmıştır. Yağ oranı Matthäus ve Brühl (2001) tarafından bildirilen metod ile Soxhlet ekstraktörü (Soxtherm 2000 automatic, Gerhardt, Germany) ile yapılmıştır. Yağ asitleri kompozisyonu analizi Sampaio ve ark. (2012) tarafından bildirilen metod revize edilerek yapılmıştır. $0.1 \mathrm{~g}$ yağa $10 \mathrm{ml}$-hekzan eklenip çalkalanarak üzerine $0.5 \mathrm{ml} 2 \mathrm{~N}$ metanollü $\mathrm{KOH}$ ilave edilip karıştıılıp 30 dakika bekletilerek esterleşme sağlanmıştır. Üst fazdan alınan örnekler Shimadzu AOC-20i otomatik enjektörüne yerleştirilmiştir. Yağ asidi kompozisyonunu belirlemede Shimadzu GC-2010 (Japonya), alev iyonizasyon dedektörü (FID) ve Teknokroma Kapillar kolon (100 m x 0.25 mm ve $0.2 \mu \mathrm{m}$ film kalınlığı) kullanılmıştır. Taşıyıcı gaz olarak helyum $0.94 \mathrm{ml} /$ dakika akış hızı ile uygulanmıştır. Split oranı 1:100 olarak ayarlanmıştır. Çalışma sıcaklıkları enjeksiyon bloğu ve detektör için $250^{\circ} \mathrm{C}$ olarak ayarlanmıştır. Kolon fırınının İzotermal kondisyonu, $140{ }^{\circ} \mathrm{C}$ 'de 5 dakika bekleyip $4{ }^{\circ} \mathrm{C} \mathrm{dk}-1$ ISı artış hızıyla $240{ }^{\circ} \mathrm{C}$ çıkarak $20 \mathrm{dk}$ bekleyecek şekilde programlanmıştır. Yağ asitlerinin tanımlanmasında standart olarak Restek 35077, Food Industry FAME mix (ABD) kullanılmıştır. Analizler Shimadzu GC-2010 (Kyoto, Japan) gaz kromotografisi kullanılarak yapılmıştır.

Ölçülen bitkisel özellik değerleri parsellerden rastgele seçilen 20 bitki ortalamasından elde edilmiştir. Dekara tohum ve yağ verimleri $9 \mathrm{~m}^{2}$ olan parsel verimleri üzerinden hesaplanmıştır. Olgunlaşma gün sayısı ekim tarihi ile tam olgunlaşma tarihi arasındaki gün hesaplanarak elde edilmiştir. Bin tane ağırlığı, 100 adet tohum hassas terazide tartılarak 4 tekrarın ortalaması ile hesaplanmıştır. 
Çalışmada elde edilen verilerin varyans analizi JMP 13 istatistiksel yazılım programı (SAS Institute, Cary, NC) kullanılarak yapılmış, aralarındaki fark önemli bulunan ortalamalar LSD çoklu karşılaştırma testi ile gruplandırılmıştır.

\section{BULGULAR VE TARTIŞMA}

Pelemir genotiplerinde incelenen iki yıla ait (2016 ve 2017) tarımsal ve teknolojik özelliklere ait değerler ile yapılan varyans analizi Çizelge 1 'de verilmiştir.

Çizelge 1. Pelemir genotiplerinde alınan gözlemler ve değerlere ilişkin varyan analizi.

Table 1. Analises of variance of observation data in Cephalaria syriaca L. genotypes.

\begin{tabular}{|c|c|c|c|c|c|c|}
\hline \multirow[b]{2}{*}{$\begin{array}{l}\text { Varyasyon } \\
\text { Kaynağı }\end{array}$} & \multicolumn{6}{|c|}{ Kareler ortalaması } \\
\hline & $\begin{array}{l}\text { Serbestlik } \\
\text { D. }\end{array}$ & $\begin{array}{l}\text { Bitki } \\
\text { boyu }\end{array}$ & $\begin{array}{l}\text { Olgunlaşma gün } \\
\text { sayısı }\end{array}$ & $\begin{array}{l}\text { Dekara tohum } \\
\text { verimi }\end{array}$ & $\begin{array}{l}\text { Bin tane } \\
\text { ağırlığı }\end{array}$ & $\begin{array}{l}\text { Dekara yağ } \\
\text { verimi }\end{array}$ \\
\hline Bloklar & 2 & 659.75 & $45.72^{*}$ & $604.53^{*}$ & $11.9^{*}$ & $187547^{*}$ \\
\hline Yıl & 1 & $2112.5^{\star *}$ & $382.72^{\star *}$ & $17672^{\star *}$ & 3.21 & $6237946^{\star *}$ \\
\hline Genotip & 2 & 44.88 & $108.22^{\star *}$ & $18240.61^{\star *}$ & $33.17^{\star \star}$ & $5521012.5^{\text {** }}$ \\
\hline Yılx Genotip & 2 & 103.74 & 0.89 & 3815.32 & 2.04 & $1344630^{\star *}$ \\
\hline Hata & 10 & 201.75 & 8.06 & 84.6 & 2.09 & 39268 \\
\hline LSD (YII) & - & 3.01 & 0.6 & 1.95 & - & 41.92 \\
\hline LSD (Genotip) & - & - & 0.74 & 2.39 & 0.38 & 51.35 \\
\hline \multirow{2}{*}{$\begin{array}{l}\text { LSD (Yll x } \\
\text { Genotip) }\end{array}$} & - & - & - & 3.37 & - & 72.62 \\
\hline & & $\begin{array}{l}\text { Yağ } \\
\text { oranı }\end{array}$ & $\begin{array}{l}\text { Miristik asit } \\
\text { (C14:0) }\end{array}$ & $\begin{array}{l}\text { cis-10-Pentadecanoic } \\
\text { asit (C15:1) }\end{array}$ & $\begin{array}{l}\text { Oleik asit } \\
\text { (C18:1) }\end{array}$ & $\begin{array}{l}\text { Linoleik } \\
\text { asit (C18:2) }\end{array}$ \\
\hline Bloklar & 2 & 0.85 & 8.41 & 1.29 & $15.15^{* *}$ & 33.06 \\
\hline Yıl & 1 & 2.75 & 3.92 & 1.44 & 0.19 & 1.5 \\
\hline Genotip & 2 & $35.54^{\star \star}$ & 0.47 & 0.09 & 0.08 & 0.98 \\
\hline Yılx Genotip & 2 & 0.88 & 0.12 & 0.02 & 0.64 & 2.25 \\
\hline Hata & 10 & 1.22 & 3.32 & 0.61 & 1.77 & 20.04 \\
\hline LSD (YIl) & - & - & - & - & - & - \\
\hline LSD (Genotip) & - & 0.29 & 0.47 & - & - & - \\
\hline $\begin{array}{l}\text { LSD (Yıl x } \\
\text { Genotip) }\end{array}$ & - & - & - & - & - & - \\
\hline
\end{tabular}

${ }^{*} 0.05,{ }^{* *} 0.01$ intimal seviyesinde önemlidir.

Tarımsal özellikler arasında bitki boyu, miristik asit, cis-10-Pentadecanoic asit, oleik asid ve linoleik asit bakımından genotipler arasındaki farklııklar önemsiz bulunmuştur. Olgunlaşma gün sayısı, dekara tohum verimi, bin tane ağırlığı, dekara yağ verimi ve yağ oranı bakımından genotipler arasında \%1 seviyesinde önemli farklılıklar ortaya çıkmıştır. Bitki boyu, yağ oranı, miristik asit, cis-10-Pentadecanoic asit ve linoleik asit için bloklar arasındaki farklılık istatistiksel olarak önemsiz bulunurken, olgunlaşma gün sayısı, dekara tohum verimi, bin tane ağılığı, dekara yağ verimi ve oleik asit bakımından bloklar arasındaki fark istatistiki bakımdan önemli bulunmuştur. Bitki boyu, olgunlaşma gün sayısı, dekara tohum verimi ve dekara yağ verimi bakımından yıllar arasındaki fark 0.01 düzeyinde önemli bulunurken incelenen diğer özellikler için istatistiki anlamda bir fark ortaya çıkmamıştır. Dekara tohum verimi ve dekara yağ verimi bakımından Genotip x Yıl interaksiyonu istatistiksel olarak 0.01 düzeyinde önemlilik göstermiştir (Çizelge 1).

Yağlı tohumlu bitkilerde seleksiyon kriterlerinin başında tohum verimi, yağ oranı ve yağ verimi gelmektedir. Pelemirde tohum verimini belirleyen diğer bir faktör olan 1000 tane ağırlığında Yıl x Genotip interaksiyonu önemsiz bulunmuştur (Çizelge 1). Tohum verimini yükseltmek diğer birçok tarla bitkisinde olduğu gibi pelemirde 
de en önemli ıslah amacıdır (Röbbelen ve ark. 1989; Uysal ve ark. 2006). Bu araştırmada tohum verimi bakımından genotipler, yıl ve yıl x genotip interaksiyonu arasındaki farklılıklar istatistiksel olarak önemli $(P<0.01)$ bulunmuştur. en yüksek tohum verimi Adana-1 genotipinde $208.6 \mathrm{~kg} \mathrm{da}^{-1}$ ile 2017 yılında ve istatistiksel olarak aynı grupta olarak 2016 yılında $197.5 \mathrm{~kg} \mathrm{da}^{-1}$ ile Karahan çeşidinde tespit edilmiştir. En düşük tohum verimi ise $59.9 \mathrm{~kg} \mathrm{da}^{-1}$ ile Sivas-1 genotipinde 2016 yılında tespit edilmiştir (Çizelge 1). Aynı genotiplerle susuz koşullarda beş farklı lokasyonda yapılan çalışmalardan $41.1-233.2 \mathrm{~kg} \mathrm{da}^{-1}$ tohum verimi alındığı, uygun ekolojik koşullarda ise Karahan çeşidinden $338.3 \mathrm{~kg} \mathrm{da}^{-1}$ a kadar verim alınabildiği bildirilmektedir (Arslan ve ark. 2014).

Pelemir çeşit ve hatlarının incelenen tarımsal özelliklerine ilişkin elde edilen 2016 ve 2017 yılları ortalama değerleri ve oluşan gruplar Çizelge 2'de verilmiştir.

Çizelge 2. Pelemir genotiplerinin morfolojik ve kalite özelliklerine ait ortalamalar ve oluşan gruplar.

Table 2. Averages and groups of morphological and quality characteristics of Cephalaria syriaca L. genotypes.

\begin{tabular}{|c|c|c|c|c|c|c|c|c|c|}
\hline \multirow[t]{2}{*}{ Genotipler } & \multicolumn{3}{|c|}{ Bitki boyu (cm) } & \multicolumn{3}{|c|}{ Olgunlaşma gün sayısı (gün) } & \multicolumn{3}{|c|}{ Tohum Verimi $\left(\mathrm{kg} \mathrm{da}^{-1}\right)$} \\
\hline & 2016 & 2017 & Ort. & 2016 & 2017 & Ort. & 2016 & 2017 & Ort. \\
\hline Karahan & 135.2 & 120.9 & 128.1 & 222.0 & 231.0 & $226.8 a$ & $105.2 b$ & $197.5 a$ & $162.9 a$ \\
\hline Adana-1 & 135.5 & 115.5 & 125.5 & 222.0 & 232.0 & $226.2 a$ & $117.2 b$ & $208.6 a$ & $151.4 b$ \\
\hline Sivas-1 & 137.9 & 107.3 & 122.6 & 215.0 & 223.3 & $219.2 b$ & $59.9 c$ & $64.4 \mathrm{c}$ & 62.2 \\
\hline Ortalama & $136.2 \mathrm{a}$ & $114.6 \mathrm{~b}$ & & $219.7 b$ & $228.8 a$ & & $94.1 \mathrm{~b}$ & $156.8 \mathrm{a}$ & \\
\hline \multirow[t]{2}{*}{ Genotipler } & \multicolumn{3}{|c|}{ Bin tane ağırlığı (g) } & \multicolumn{3}{|c|}{ Yağ verimi kg da-1) } & \multicolumn{3}{|c|}{ Yağ oranı (\%) } \\
\hline & 2016 & 2017 & Ort. & 2016 & 2017 & Ort. & 2016 & 2017 & Ort. \\
\hline Karahan & 18.0 & 16.8 & 19.0a & $2284.0 \mathrm{~b}$ & $3968.9 a$ & 20.0 & 21.8 & 20.1 & $32.5 a$ \\
\hline Adana-1 & 19.8 & 18.1 & $17.4 a$ & $2365.7 b$ & 4127.9a & 20.9 & 20.2 & 19.8 & $31.3 a$ \\
\hline Sivas-1 & 14.1 & 14.6 & $14.3 b$ & $1485.9 c$ & $1570.9 c$ & 24.6 & 24.8 & 24.4 & $15.5 b$ \\
\hline Ortalama & 17.3 & 16.5 & & $2045.2 b$ & $3222.6 a$ & & 22.2 & 21.5 & \\
\hline \multirow[t]{2}{*}{ Genotipler } & \multicolumn{3}{|c|}{ Miristik asit (C14:0) (\%) } & \multicolumn{3}{|c|}{ cis-10-Pentadecanoic asit (C15:1) (\%) } & \multicolumn{3}{|c|}{ Oleik asit (C18:1) (\%) } \\
\hline & 2016 & 2017 & Ort. & 2016 & 2017 & Ort. & 2016 & 2017 & Ort. \\
\hline Karahan & 14.3 & 17.2 & 15.5 & 7.9 & 7.4 & 7.7 & 28.1 & 29.0 & 30.0 \\
\hline Adana-1 & 14.7 & 17.4 & 15.2 & 8.7 & 7.6 & 7.6 & 29.7 & 29.9 & 29.8 \\
\hline Sivas-1 & 15.0 & 17.8 & 14.9 & 7.7 & 7.5 & 7.5 & 30.5 & 29.5 & 29.8 \\
\hline Ortalama & 14.7 & 17.5 & & 8.1 & 7.5 & & 29.4 & 29.5 & \\
\hline \multirow[t]{2}{*}{ Genotipler } & \multicolumn{3}{|c|}{ Linoleik asit (C18:2) (\%) } & & & & & & \\
\hline & 2016 & 2017 & Ort. & & & & & & \\
\hline Karahan & 30.6 & 29.3 & 30.6 & & & & & & \\
\hline Adana-1 & 31.2 & 33.7 & 30.0 & & & & & & \\
\hline Sivas- 1 & 30.0 & 30.2 & 29.8 & & & & & & \\
\hline Ortalama & 30.6 & 31.1 & & & & & & & \\
\hline
\end{tabular}

Araştırmada kullanılan genotiplerde bitki boyu değerleri arasındaki fark istatistiki olarak önemsiz olmakla birlikte, genotiplerin ortalama bitki boyu $122.6-128.0 \mathrm{~cm}$ arasında değişmiştir. İki yıl ortalamasına göre Karahan çeşidi $128.0 \mathrm{~cm}$ ile en fazla boylanan, Sivas-1 genotipi ise $122.6 \mathrm{~cm}$ ile en az boylanan genotip olmuş, Sivas-1 genotipinin ise $125.5 \mathrm{~cm}$ ile diğer iki genotipin arasında kaldığı saptanmıştır (Çizelge 2). Ada ve Tamkoç (2015) Sivas ilinden temin ettikleri 33 genotiple Konya ekolojik şartlarında yapmış oldukları çalışmada bitki boyunu 50.4$108.6 \mathrm{~cm}$ arasında tespit ettiklerini bildirmişlerdir. Yine aynı şekilde Arslan ve ark. (2014)'nın Ankara ekolojik şartlarında Karahan çeşidiyle yaptıkları iki yıllık bir çalışmada bitki boyunu 96.2-183.0 cm arasında tespit ettiklerini bildirmişlerdir. Çağlar (1968)'ın yaptığı çalışmada ise bitki boyu $100 \mathrm{~cm}$ olarak bildirilmiştir. Pelemir bitkisinin bitki boyu özelliğinin hem genotipik olarak hem de çevresel faktörlere bağlı olarak oldukça varyasyon gösterdiği görülmüştür. Pelemir bitkisinde, ana sap üzerinde birincil yan dallar ve bunların üzerinde de ikincil yan dallar meydana gelmektedir. Hem birincil hem de ikincil dallar birer başçı ile son bulmaktadır. Pelemir bitkisinde bitki boyu arttıkça dal sayısı ve buna bağlı olarak başçık sayısı artmaktadır. Bu nedenle pelemir bitkisinde bitki boyu 
dolaylı olarak başçık sayısına etki etmekte ve başçık sayısının artışı da tohum verimini artırmaktadır (Katar ve ark. 2012, Arslan ve ark. 2014).

Bir yağ bitkisi olan pelemirde en önemli verim kriteri tohumun yağ oranıdır. Yağ oranı iki deneme yılı ortalamasına göre en yüksek Sivas-1 genotipinde görülürken, en düşük yağ oranı Adana-1 genotipinde tespit edilmiştir. Ancak yağlı tohumlu bitkiler için asıl önemli olan kriter dekara yağ verimi olduğu için en yüksek yağ verimi değerine $32.5 \mathrm{~kg} \mathrm{da} a^{-1}$ ile Karahan çeşidinde ulaşılmıştır. En düşük yağ verimi ise $15.5 \mathrm{~kg} \mathrm{da}^{-1}$ Sivas-1 $^{-1}$ genotipinden elde edilmiştir. Denemeden elde edilen yağ oranı, Ada ve Tamkoç (2015)'un bulduğu \%19.8-33.7, Arslan ve ark. (2012)'nın Karahan çeşidi için bulduğu \%17.7-21.4, Sezgin ve ark. (2017)'nın aynı genotipler için bulduğu \%19.8-24.4 oranlarıyla yakın değerler göstermektedir. Ancak çevre şartlarına bağı olarak yağ oranları kısmen de olsa farklılıklar göstermiştir.

Araştırmada, pelemir genotipleri ortalama olarak \%14.8-15.5 arasında miristik asit, \%7.5-7.7 arasında cis-10Pentadecanoic asit, \%29.8- 30.0 arasında oleik asit ve \%29.8-30.6 arasında linoleik asit içermişlerdir (Çizelge 2). Her iki deneme yılı ortalamasına bakıldığında genotipler arasında yağ asitleri bakımından bir farklılık gözlenmemiştir. Yağındaki toplam doymamış yağ asidi oranı oldukça yüksek olmakla birlikte dağılım oranı da dengelidir. Pelemir yağında, zeytinyağını sağlıklı ve oksidasyona dayanıklı yağ sınıfına sokan oleik asit oranının istenen düzeyde olmasının yanı sıra esansiyel yağ asitlerinden biri olan linoleik asidin oranı da sağlıklı bir yağda olması gereken miktardadır.

\section{SONUÇ}

Pelemir yağı yağ asitleri kompozisyonu itibarı ile yemeklik olarak uygun görülmekle birlikte, Yazıcıoğlu ve ark. (1978) tarafından bildirilen epoksi yağ içeriği ile ilgili detaylı bir çalışma yapılması gerekmektedir. Ancak endüstriyel anlamda da büyük bir yağ açığına sahip olan Türkiye'nin coğrafi koşullarına uygun ve soğuğa dayanımı yüksek bu bitkinin önemli bir potansiyeli vardır. Bu çalışma sonucunda elde edilen değerlerin varyans analizinde Karahan ve Adana-1 genotipinin tane ve yağ verimi bakımından öne çıktığı görülmüştür. Yağ oranı bakımından Sivas-1 genotipi öne çıkmış olsa da yağ verimi bakımından en düşük değeri almıştır. Tüm bu veriler dikkate alındığında Karahan genotipinin kışa dayanımının, tohum veriminin, yağ veriminin ve yağ oranının yüksek olması nedeniyle kışlık pelemir çeşidi olarak önemli bir alternatif yağ bitkisi olabileceği değerlendirilmiştir.

\section{ÇIKAR ÇATIŞMASI}

Yazarlar arasında herhangi bir çıkar çatışması mevcut değildir.

\section{YAZAR KATKISI}

Oğuzhan Aydın, Faheem Shehzad Baloch, Mahmut Çamlıca ve Vahdettin Çiftçi arazi çalışmalarının yürütülmesine katkı sağlamışlardır. İlhan Subaşı ve Yusuf Arslan makalenin yazılması, arazi ve laboratuvar çalışmalarının gerçekleştirilmesi ve istatistik analizinin yapılmasında katkı sağlamışlardır.

\section{KAYNAKLAR}

Ada, R., \& Tamkoc, A. (2015). Some Agricultural Characteristics of the New Cephalaria syriaca L. Genotypes Developed for Arid Areas. Selcuk Journal of Agriculture and Food Sciences, 29(1), 25-30.

Arıoğlu, H., Kolsarıcı, Ö., Göksu, A. T., Güllüoğlu, L., Arslan, M., Çalışkan, S., Söğüt, T., Kurt, C., \& Arslanoğlu, F. (2010). Yağ bitkileri üretiminin artırılması olanakları, Türkiye Ziraat Mühendisliği 7. Teknik Kongresi, Adana.

Arslan, Y., Katar, D., Subaşı, I., \& Kodaş, R. (2012). Farklı azot ve fosfor dozlarının pelemir bitkisi (Cephalaria syriaca L.)'nin verim ve yağ oranı üzerine olan etkisinin belirlenmesi, I. Uluslararası Iğdır Sempozyumu, Iğdır.

Arslan, Y., Subaşı, I., Kodaş, R., \& Katar, D. (2014). Farklı Azot ve Fosfor Seviyelerinin Kuru Şartlarda Yetiştirilen Pelemir (Cephalaria syriaca L.) Bitkisinin Verim ve Verim Özellikleri Üzerine Etkisi, Süleyman Demirel Üniversitesi Ziraat Fakültesi Dergisi, 9(2), 3-41.

Çağlar, H. (1968). Pelemir El Kitabı. Güven Matbaası, Ankara. 
Karaoğlu, M. (2012). Effect of Cephalaria syriaca addition on rheological properties of composite flour. International Agrophysics, 26, 387-393.

Katar, D., Arslan, Y., Kayaçetin, F., Bayramin, S., \& Karahan, Y. (2011). Ankara ekolojik koşullarında farklı sıra aralıklarının pelemir bitkisi (Cephalaria cyriaca (sirjaca) L.)'nin verim ve verim unsurları üzerine etkisinin belirlenmesi I. Ali Numan Kıraç Tarım Kongresi ve Fuarı, Eskişehir.

Katar, D., Arslan, Y., Subaşı, I., \& Kodaş, R. (2012). The effect of different sowing dates on yield and yield components of Cephalaria (Cephalaria syriaca) under Ankara ecological condition. Biological Diversity and Conservation, 5(3), 48-53.

Matthäus, B., \& Brühl, L. (2001). Comparison of different methods for the determination of the oil content in oilseeds. Journal of the American Oil Chemists' Society 78, 95-102.

Mubiru, E., Shrestha, K., Papastergiadis, A., \& Meulenaer, B. (2013). Improved gas chromatography-flame ionization detector analytical method for the analysis of epoxy fatty acids. Journal of Chromatography A, 1318, 217-225.

Öğüt, H., Oğuz, H., Bacak, S., Aydın, F., Uygun, S., Arslan, Y., \& Subaşı, İ. (2014). Pelemir biyodizelinin teknik özelliklerinin incelenmesi. Enerji Tarımı ve Biyoyakıtlar 4. Ulusal Çalıştayı, Samsun.

Röbbelen, G., Downey, R.K., \& Ashri, A. (1989). Oilcrops of the World, McGraw-Hill, United States.

Sampaio, G. R, Saldanha, T., Soares, R. A. M., \& Torres, E. A. F. S. (2012). Effect of natural antioxidant combinations on lipid oxidation in cooked chicken meat during refrigerated storage. Food Chemistry, 135(3), 1383-1390.

Sezgin, M., Tezcan, H., Şahin, M., Arslan, Y., Subaşı, I., Demir, I., \& Koç, H. (2017). Bazı pelemir (Cephalaria syriaca L.) genotiplerinin Türkiye'nin farklı ekolojik koşullarında verim ve kalite değerlerinin belirlenmesi. Kahramanmaraş Sütçü İmam Üniversitesi Tarım ve Doğa Dergisi, 20(Özel Sayı), 192-195.

TTSM. (2017). Milli çeşit listesi. https://www.tarimorman.gov.tr/BUGEM/TTSM/Sayfalar/Detay.aspx?Sayfald=85. Erişim tarihi: 23 Aralık 2020.

TÜiK. (2019). Bitkisel üretim istatistikleri. https://data.tuik.gov.tr/Bulten/Index?p=Bitkisel-Uretim-Istatistikleri-2019-30685. Erişim tarihi: 27 Kasım 2019.

Uysal, N., Baydar, H., \& Erbaş, S. (2006). Isparta populasyonundan geliştirilen Aspir (Carthamus tinctorius L.) hatlarının tarımsal ve teknolojik özelliklerinin belirlenmesi. Süleyman Demirel Üniversitesi Ziraat Fakültesi Dergisi, 1(1), 52-63.

Yazıcıoğlu, T., \& Karaali, A. (1983). Türk Bitkisel Yağlarının Yağ Asitleri Bileşimleri. Tübitak, Marmara Bilimsel ve Endüstriyel Araştırma Enstitüsü, Yayın No: 70.

Yazıcıoğlu, T., Karaali, A., \& Gökçen, J. (1977). Pelemir Tohumu Yağı ve Küspesi Üzerinde Bir Araştırma. T.B.T.A.K. Marmara B.A.E., Beslenme ve Gıda Teknik Ünitesi, Proje Rap. No: 2807. 